\title{
A gigantic jet event observed over a thunderstorm in mainland China
}

\author{
YANG Jing $^{1 *} \&$ FENG GuiLi ${ }^{2}$ \\ ${ }^{1}$ Key Laboratory of Middle Atmosphere and Global Environment Observation (LAGEO), Institute of Atmospheric Physics, Chinese Academy of \\ Sciences, Beijing 100029, China; \\ ${ }^{2}$ Shandong Research Institute of Meteorology, Jinan 250031, China
}

Received June 6, 2012; accepted July 23, 2012; published online November 10, 2012

Gigantic jet (GJ) is a type of large-scaled transient discharge which occurs above thunderstorms. It connects the thunderstorms and ionosphere directly. Compared with the other transient luminous events (TLEs), gigantic jet is very difficult to be seen from the ground. We report a GJ event that was clearly recorded in eastern China (storm center located at $35.6^{\circ} \mathrm{N}, 119.8^{\circ} \mathrm{E}$, near the Huanghai Sea) at 20:16:22 (local time) on 12 August, 2010. It is by far the furthest from the equator ground-based GJ recorded over summer thunderstorm. The top altitude of this GJ was estimated to be about $89 \mathrm{~km}$. The GJ-producing storm was a multi-cell thunderstorm and the GJ event occurred in the storm developing stage, with the lowest cloud-top brightness temperature about $-73^{\circ} \mathrm{C}$ and the maximum radar echo top around $17 \mathrm{~km}$. Altitudes with reflectivity of $45 \mathrm{dBZ}$ were estimated to reach $12-14 \mathrm{~km}$. Different from results from other countries that positive CGs (Cloud-to-ground lightnings) dominated during a time period centered at GJ, our study shows that negative CGs dominated during a time period centered at the GJ event and during most of the storm lifetime in this study, indicating a diversity of the lightning activity in the GJ-producing storms. It is interesting that two different storms produced two types of TLEs, that is, the GJ-producing storm only produced one GJ event during its lifetime and five sprites were produced over another storm, different from the other study that sprites and GJs were usually produced by the same storm, enriched the knowledge of GJ-producing storms. In addition, the GJ event in this study is located beyond the effective coverage area $\left(30^{\circ} \mathrm{S}-30^{\circ} \mathrm{N}\right)$ of the ISUAL instruments onboard the FORMOSAT II satellite, and results of this study could be useful for GJ studies in the future.

gigantic jet, lightning, thunderstorm, sprite

Citation: $\quad$ Yang J, Feng G L. A gigantic jet event observed over a thunderstorm in mainland China. Chin Sci Bull, 2012, 57: 4791-4800, doi: 10.1007/s11434-0125486-3

When talking about lightning, images of different lightning occuring along with thunderstorms will emerge in the minds of the people. These lightnings occur in the troposphere and have been extensively studied [1-11]. However, there are another type of lightning discharges which occur above the thunderstorms, with the top altitude even reaching the ionosphere. Up to now, lightning discharges above storms include sprite [12-14], elves (Emissions of Light and VLF perturbation due to EMP Sources) [15], blue jet [16] and gigantic jet [17]. Owing to their short duration time (in the order of ms), these discharges are named as Transient Lu-

*Corresponding author (email: yangj@mail.iap.ac.cn) minous Events (TLEs).

On the evening of 15 September 2001, a gigantic jet event was recorded by Pasko et al. [17] and the discharge propagating upwards from the thundercloud to an altitude of 70-90 km, the dominated optical emission was blue. This discharge event was not named as "gigantic jet" at that time but named by Pasko et al. [17] as "electrical discharge from a thundercloud top to the lower ionosphere". Five similar discharges were recorded by $\mathrm{Su}$ et al. [18] from Cheng Kung University over a thunderstorm near Luzon Island, and this kind of discharge was first named as "gigantic jet". Thereafter, Van der Velde et al. [19], Cummer et al. [20], and Chou et al. [21] reported gigantic jet observations, re- 
spectively. However, Soula et al. [22] reported five gigantic jets over an isolated thunderstorm.

Van der Velde et al. [19] showed that the bright lower channel of the gigantic jet ended in a fork at around 50$59 \mathrm{~km}$ height with very dim upper branches extended to $69-80 \mathrm{~km}$. During the time window containing the gigantic jet, there was a larger and slower charge moment change of $520 \mathrm{Ckm}$ over $70 \mathrm{~ms}$. Based on simultaneous low-light video images and low-frequency magnetic field measurements, Cummer et al. [20] reported a total charge of $144 \mathrm{C}$ for the assumed channel length of $75 \mathrm{~km}$, and their results confirmed the negative polarity of gigantic jets. Chou et al. [21] reported a gigantic jet over Fujian Province, and the gigantic jet begins with a blue starter, then a blue jet occurs at the same cloud top after $100 \mathrm{~ms}$ and finally develops into a gigantic jet $\sim 50 \mathrm{~ms}$ later. This gigantic jet was the first recorded Type-II gigantic jet from the ground (classifications of gigantic jet are given in section 2). Soula et al. [22] studied five gigantic jets observed at a very close distance of $50 \mathrm{~km}$. Three of the five gigantic jets occurred before the storm reached its coldest cloud top temperature $\left(-81^{\circ} \mathrm{C}\right)$ and the other two occurred during the cloud extension. The extremely low frequency (ELF) data showed that the five gigantic jets reported by Soula et al. [22] were also negative discharges.

In summary, gigantic jets reported by previous studies occurred in tropical or subtropical regions. Van der Velde et al. [23] described a gigantic jet over a winter thunderstorm. It is clear that gigantic jets occurring over summer or winter storms are very limited. Meanwhile, those results also showed that gigantic jet occurrence is sporadic compared with sprite, elves etc. Results from instruments of ISUAL (Imager of Sprites and Upper Atmospheric Lightnings) onboard Taiwan FORMOSAT II satellite showed that 5434 elves, 633 sprites and only 13 gigantic jets were recorded from July 2004 to June 2007 [24], indicating gigantic jet occurrence rate is relatively low. Therefore, knowledge of gigantic jet and its associated thundercloud is very limited due to the very limited cases.

In this study, a gigantic jet event occurred over a thundercloud in Shandong Province will be analyzed. It is the first report of gigantic jet in mainland China. As mentioned in previous paragraphs, most of the gigantic jets of previous studies occurred in tropical or subtropical, or winter thunderstorms, gigantic jet in this paper occurred in mid-latitude region $\left(35.6^{\circ} \mathrm{N}, 119.8^{\circ} \mathrm{E}\right)$ and it is the furthest from the equator documented in summer season so far. Therefore, results of this study enriched our knowledge about gigantic jet cases. Meanwhile, the location of gigantic jet in this study is beyond the effective latitudinal coverage area $\left(30^{\circ} \mathrm{S}-30^{\circ} \mathrm{N}\right)$ of the ISUAL instruments, and results of this study could be considered as a useful additional reference for GJ studies. In addition, some interesting results different from previous studies were obtained. Consequently, this study enriched our knowledge of gigantic jet and its associ- ated thunderstorm and lightning activities.

\section{Experiment and data}

The experiment site is located in Binzhou, Shandong in eastern China $\left(37^{\circ} 49^{\prime} 42^{\prime \prime} \mathrm{N}, 118^{\circ} 05^{\prime} 06^{\prime \prime} \mathrm{E}\right)$, about $40 \mathrm{~km}$ from the Huanghai Sea. The observation system consists of a monochrome CCD camera (Watec $902 \mathrm{H}$ ) and a $12 \mathrm{~mm}$ $\mathrm{f} / 0.8$ lens with field of view (FOV) of $31.1^{\circ} \times 21.2^{\circ}$ [14], the frame rate of the system is 25 frames per second. During observation, infrared weather images are used to obtain the azimuth angle and the distance of the potential thunderstorm which may produce TLEs. Meanwhile, real-time data (updated every ten minutes) from World Wide Lightning Location Network (WWLLN) are used to determine the camera pointing direction, and adjust the camera towards the center of lightning activity of the storm. The WWLLN is a Very Low Frequency (VLF) detection network which consists of more than 40 stations, and the network center is located in University of Washington. There are four stations in China, including Beijing, Lanzhou, Nanjing and Hong Kong. The instrument of Beijing station was installed on top of the experiment building. However, WWLLN could not provide lightning peak current information, so this information is given by lightning location network of Shandong Meteorological Bureau.

Data from the MTSAT satellite has been used to provide cloud top brightness temperature information of GJ-producing storm, the brighter the image pixel, the colder and higher the cloud top. This data are downloadable from internet (http://weather.is.kochi-u.ac.jp/archive-e.html) and updated every hour with spatial resolution of $0.05^{\circ} \times 0.05^{\circ}$. Detailed information of the thunderstorm is given by Doppler radar. Doppler radar is a useful tool for monitoring the Mesoscale Convective Systems (MCSs). Radar data used in this paper is obtained by a WSR-98D S-band Fully Coherent Doppler Weather radar. It is an upgraded version of the USA's WSR-88D, and shares many features including stateof-the-art computerized control, 24-h operational capability, real-time monitoring, real-time calibration, and high accuracy and reliability. The Doppler radar has two scanning ranges, one is $230 \mathrm{~km}$ and the other is $460 \mathrm{~km}$. The spatial resolution is $1 \mathrm{~km}$ with scanning range of $230 \mathrm{~km}$ and the data are updated every 6 minutes. The Doppler radar data was also provided by Shandong Meteorological Bureau. The radio sounding data was provided by University of Wyoming (weather.uwyo.edu/upperair/sounding.html) and data from Qingdao station $\left(35^{\circ} 59^{\prime} 16^{\prime \prime} \mathrm{N}, 120^{\circ} 13^{\prime} 44^{\prime \prime} \mathrm{E}\right)$ is used with the station number 54857 .

\section{Gigantic jet characteristics}

The observed gigantic jet (GJ) shown in Figure 1(a) occurred 
at 20:16:22 on 12 August 2012. Chou et al. [25] classified GJs into three types by using data obtained with ISUAL. Type-I GJs have similar characteristics as reported by Pasko et al. [17] and Su et al. [18]. Type-I GJs have three stages during its evolution, the leading jet (LJ), fully developed jet (FDJ) and trailing jet (TJ). The leading jet acts as the stepped leader in cloud-to-ground lightning (CG), and the fully developed jet is similar to the return stroke, but the trailing jet could not act as dart leader in CG which re-establishes its complete path between the thunderstorm and ionosphere. The ELF data showed that Type-I GJs are negative discharges. Type-II GJs begin as blue jets (blue jets also start from thundercloud top, but their terminal altitude is about $40-50 \mathrm{~km}$ above the ground, lower than that of GJs) and then developed into GJs and reached up to the lower ionosphere. The optical emissions of Type-II GJs were weak and were considered to be positive discharges. Type-III GJs were preceded by lightning, and the GJ subsequently occurred near this preceding lightning. The brightness of Type-III GJs was between Type-I and Type-II GJs. Figure 1(b) and (c) was GJ images obtained by other authors $[18,25]$. By comparing our results with Figure 1(b) and (c), only the upper part of the GJ was recorded in this study. Moreover, the morphology of the recorded GJ shown in Figure 1(a) was similar to that reported by Su et al. [18] (Figure 1(b)) and Chou et al. (Figure 1(c)) [25], indicating that GJ in this study may be Type-I. In addition, Chou et al. [25] found that the brightness of Type-I GJ was about 3.4 times larger than that of Type-II GJ. The GJ image in this paper was obtained from the ground even though its blue emissions were reduced by atmospheric scattering and absorption, which further confirmed that the recorded GJ was Type-I.

\section{Characteristics of GJ-producing and sprite- producing storms}

Figure 2 shows the distributions of CGs on the cloud-top brightness temperature, the black and pink dot symbols stand for negative and positive CG lightnings, respectively. It can be seen from Figure 2 that most of the lightning flashes are negative cloud-to-ground lightning (CG) and only few are positive CGs. The negative CGs clustered in low cloud-top brightness temperature region. Although it seems some negative CGs are located in high cloud-top brightness temperature region (indicated by a white circle in 24:00 figure), comparative analysis between infrared
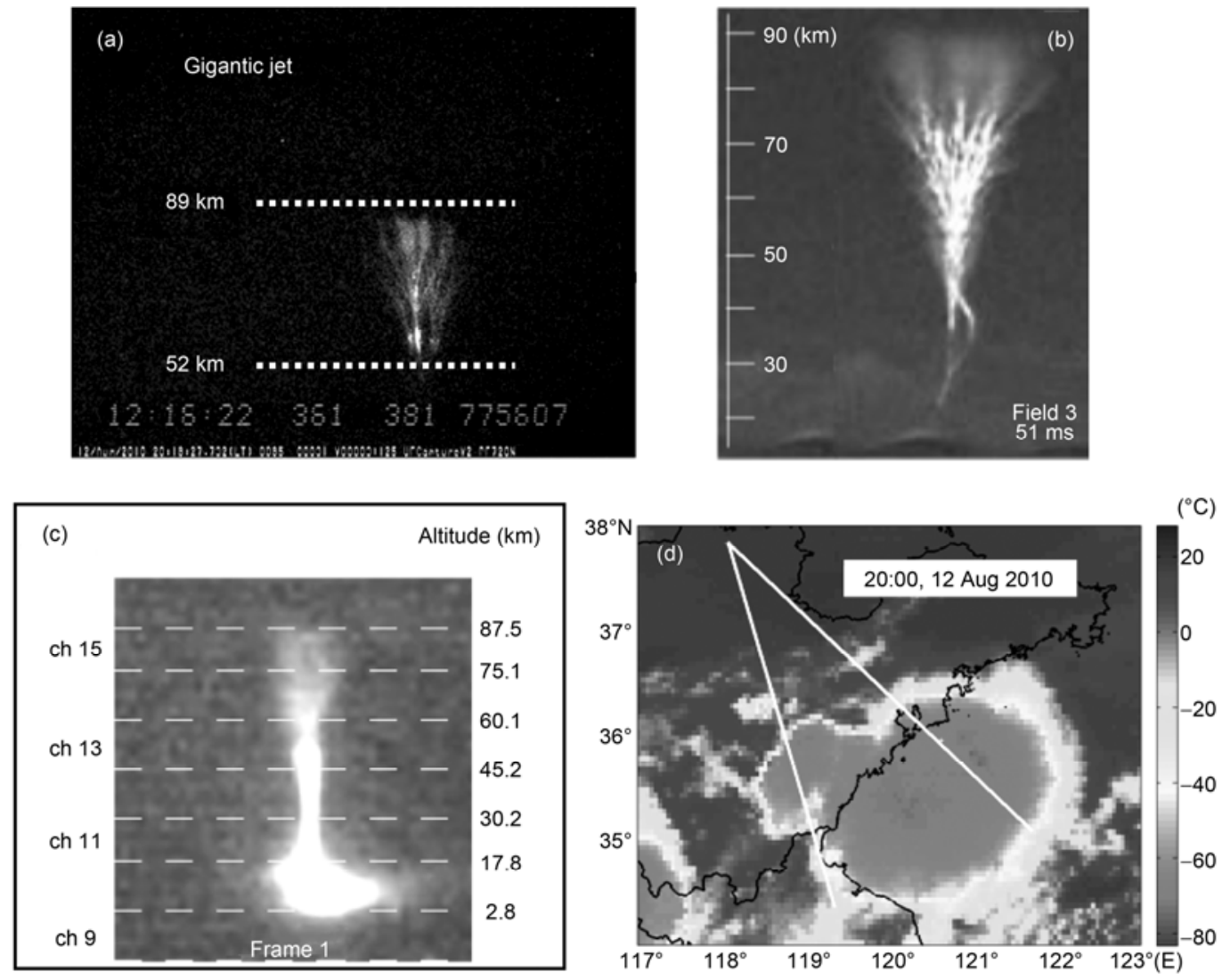

Figure 1 Gigantic jet images and their associated thunderstorms. (a) Observed GJ in this paper; (b) image of Type-I GJ by Su et al. [18]; (c) image of Type-I GJ by Chou et al. [25]; (d) cloud-top brightness temperature obtained from MTSAT satellite and the lowest temperature was about $-73^{\circ} \mathrm{C}$. The two white lines in (d) represent the range of the line-of-sight extending from the observation site. 

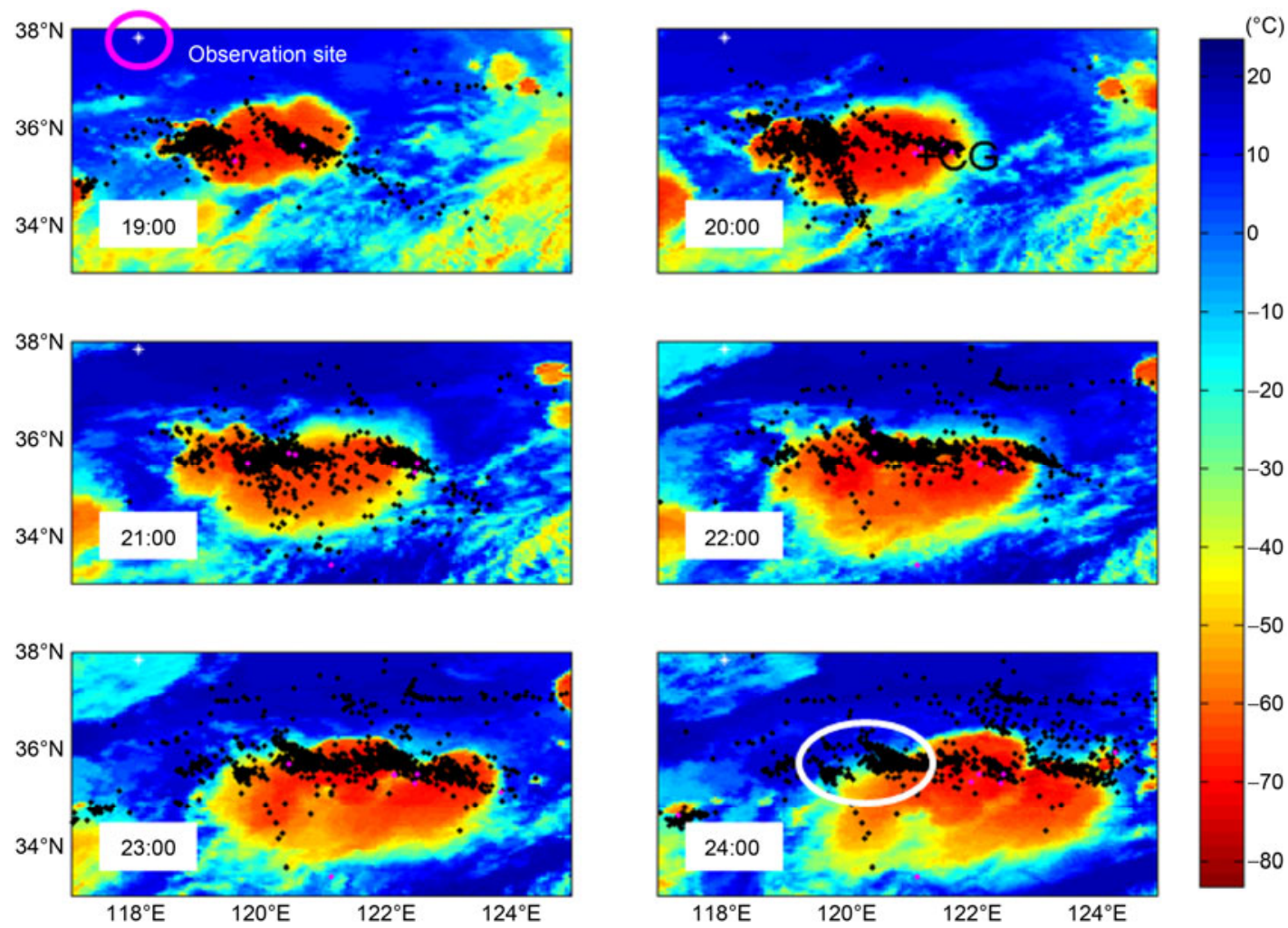

Figure 2 Cloud-top brightness temperature on 12 August, 2010 with CG flashes within an hour centered at the time shown in the figure. The black and pink dots stand for negative and positive CG lightning, respectively. The circled white asterisk shown on the 19:00 image indicates the observation site.

weather maps and radar reflectivity in Figure 3 indicated that these CGs (indicated by a white circle in 24:00 figure) were in good agreement with strong radar echoes (for clear image of the storm structure, no lightning flashes were overlapped on Doppler radar image). Images labeled with 19:00 and 20:00 in Figure 2 shows that the CGs clustered in two regions. Further analysis from Doppler radar image showed that there were two storms in the camera field of view (storm A and B in Figure 3). Due to the coarse resolution $\left(0.05^{\circ} \times 0.05^{\circ}\right)$ of the infrared map, detailed information of the storms could not be seen.

Since there are two storms in the camera field of view (marked with A and B in Figure 3), it is uncertain which storm produced the GJ, which produced the sprites, or one storm produced both the GJ and sprites. The camera field of view is overlapped with the Doppler radar images as shown in Figure 3 labeled with 20:19. Meanwhile, the azimuth of the GJ in the camera field of view is known, the GJ azimuth was also overlapped with the Doppler radar image as shown in 20:19 image. It can be seen from the image that the GJ azimuth went through the storm A's strong center and only the edge of storm B, indicating that GJ was most probably produced by storm A. Provided that the observed GJ were produced by storm B, the GJ would be in the middle or left part of the field of view, but this is not the case. Therefore, it is storm A that produced the observed GJ. Image labeled with 20:19 showed that storm A consists of two parts, one in the south and the other in the north, and the south part was stronger than the north one. It is more likely that the south part produced the GJ. But in the end which storm produced the GJ? First, we assume that the south part of storm A produced the GJ. Since the observation station location, the camera field of view, the azimuth and elevation of the observation system are known, the horizontal distance between the observation site and the storm center could be considered as the distance between the observation site and the GJ. Provided that all these information were known, the altitudes of the GJ in Figure 1(a) could be estimated by using method mentioned in Yang et al. [14]. The estimated altitude of the bottom and top of the GJ on the image are about 52 and $89 \mathrm{~km}$, respectively, consistent with results reported by other authors [17-20]. Although the north part was weaker than the south one, there was still some possibility that it produced the GJ. To clarify this question, similar calculations were made and results show that the bottom and top of the GJ on the image would be at 38 and $74 \mathrm{~km}$, respectively, much lower than that of the known results in the literature [17-20]. This leads to a conclusion that GJ was produced by the south part of storm A. Similar analysis shows that the five sprites were produced by storm B and they occurred between 19:42 and 19:57. The average time intervals between two successive sprites were about 4 minutes. The parent CGs for sprites occurred at 19:51:15 and 19:56:18 located in regions with cloud top 

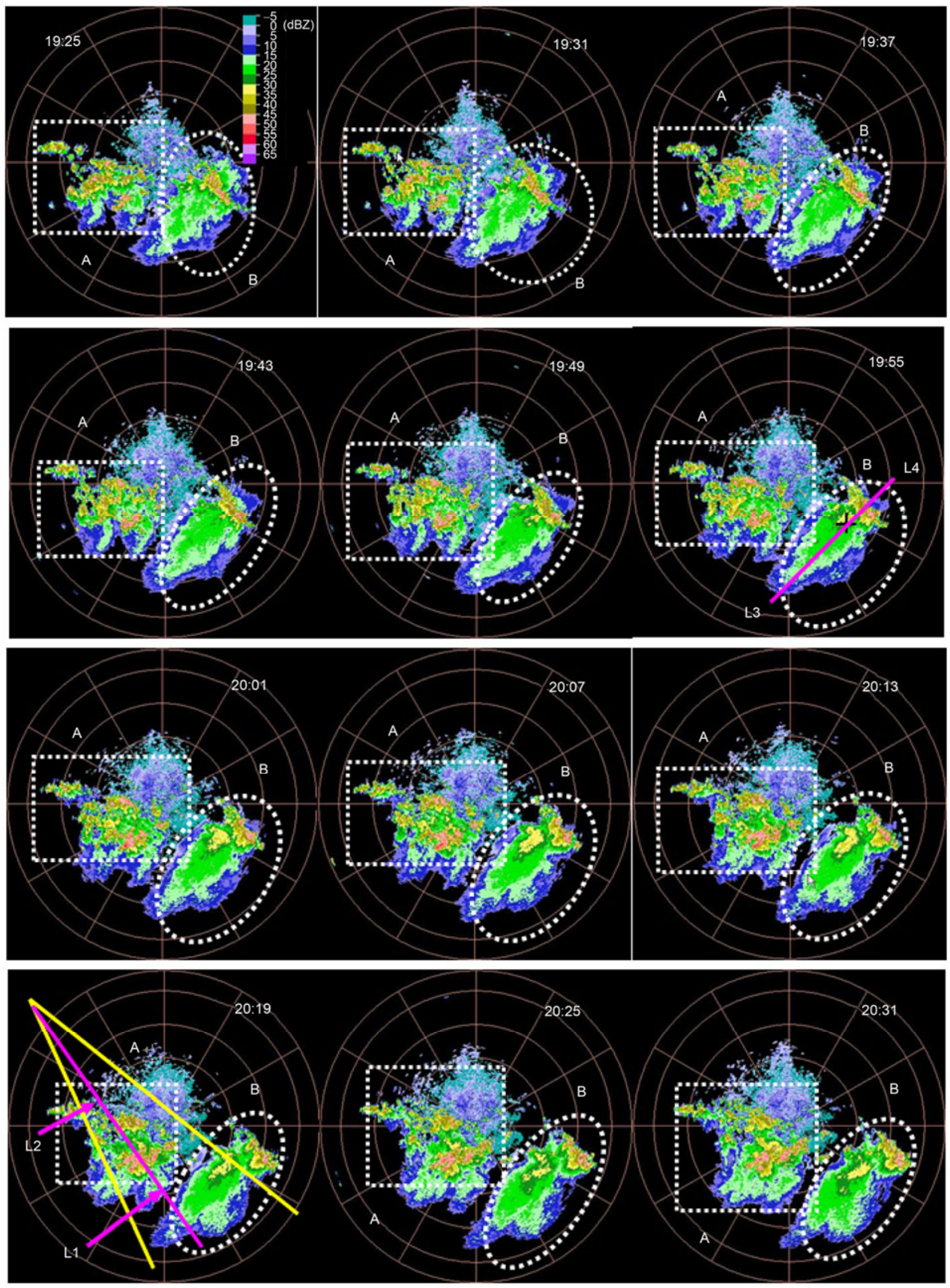

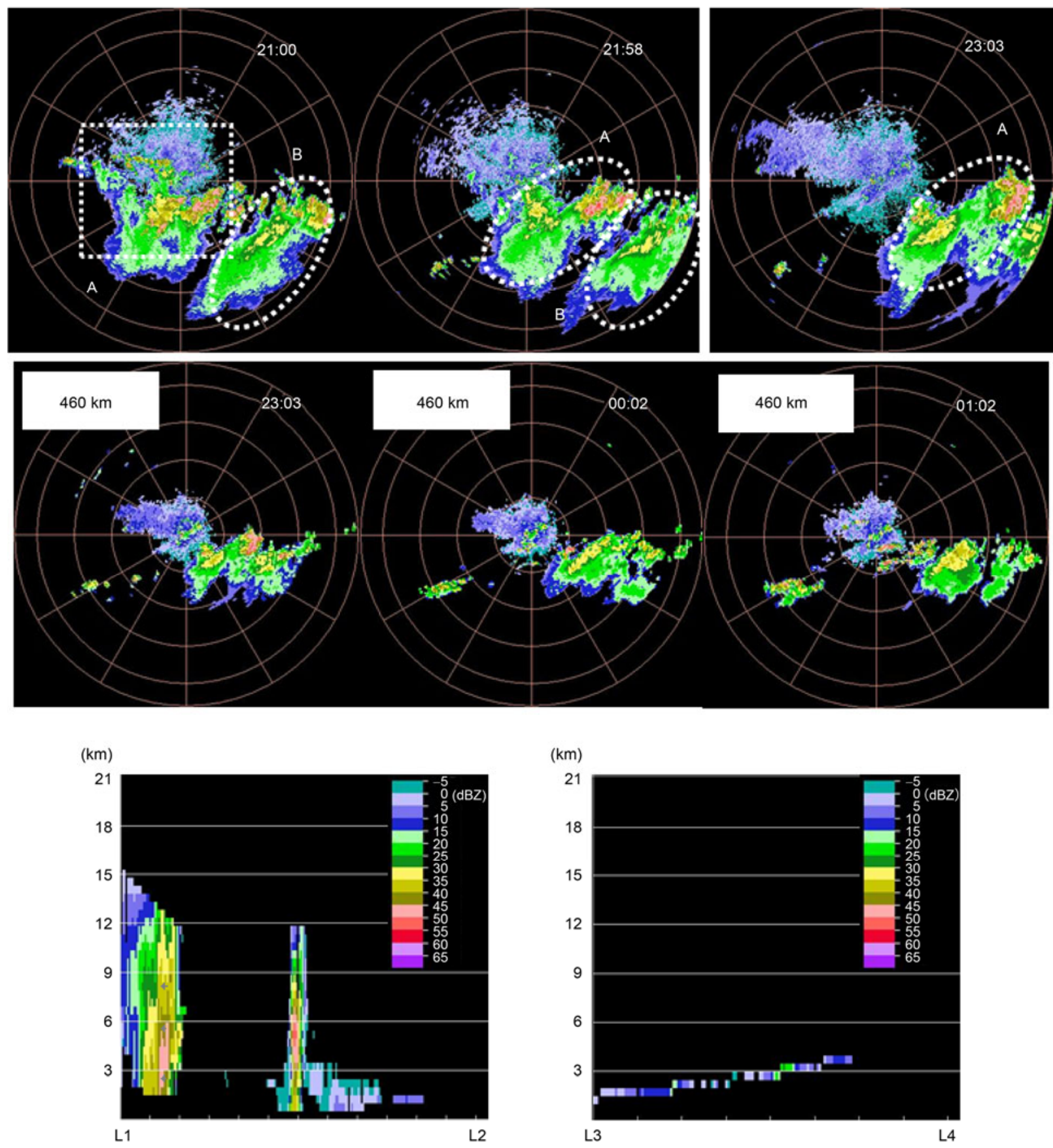

Figure 3 Evolution of the storm structure. All the images have the same color bar as in the first one labeled with 19:25. The last two images show the vertical cross sections of the radar reflectivity along line (L1, L2) in image labeled with 20:19 and line (L3, L4) in image labeled with 19:55. The two yellow lines overlapped on image marked 20:19 (three minutes after the GJ) represent the range of the line-of-sight extending from the observation site, that is, the camera FOV. The pink line in 20:19 image is the GJ azimuth in the FOV.

brightness temperature of $-70^{\circ} \mathrm{C}$. The symbol + in Figure 2 labeled with 20:00 indicated the location of parent CG. Characteristics of the GJ and five sprites are listed in Table 1. Figure 4 shows the images of the five sprites.

Van der Velde et al. [19] found that GJ and sprites occurred over the same storm. Different types of TLEs were observed in two different storms in this paper. Are there any difference between the GJ-producing storm A and sprite- producing storm B? It shows that GJ occurred in a time period in storm A with lowest cloud-top brightness temperature about $-73^{\circ} \mathrm{C}$. The cloud-top brightness temperature increased after 21:00 but decreased after 22:00. The decrease of cloud-top temperature after 22:00 may be due to the moist warm air from the Huanghai Sea which reactivated the storm convection (the storm moved toward the Huanghai Sea), leading to the decrease of cloud top brightness temperature. 
Table 1 Characteristics of the gigantic jet (GJ) and 5 sprites

\begin{tabular}{clcl}
\hline Number & \multicolumn{1}{c}{ Type } & Beijing time & Appearance \\
\hline 1 & Gigantic jet & $20: 16: 22$ & Type-I \\
2 & Sprite & $19: 42: 38$ & Carrot \\
3 & Sprite & $19: 46: 25$ & Carrot \\
4 & Sprite & $19: 49: 05$ & Unknown \\
5 & Sprite & $19: 51: 15$ & Carrot \\
6 & Sprite & $19: 56: 18$ & Carrot \\
\hline
\end{tabular}

The lowest cloud top brightness temperature was $-75^{\circ} \mathrm{C}$ in the sprite time period, a little lower than that of the previous studies [14,26]. Figure 3 shows the Doppler radar images of GJ-producing storm A and sprite-producing storm B. Radar images with small time intervals of 6 minutes were shown during the gigantic jet and sprite period (between 19:25 and 20:31 on 12 August) for showing clearly what happened in this period. And radar images with large time intervals of one hour were shown in the following hours $(21: 00,21: 58$, 23:03 on 12 August, and 00:02, 01:02 on 13 August). For seeing characteristics of radar echo of the storm clearly, radar reflectivity with scanning range of 460 or $230 \mathrm{~km}$ was shown in this paper. Images labeled with $460 \mathrm{~km}$ in Figure 3 were obtained from radar data with scanning range of $460 \mathrm{~km}$, and the other images were obtained with scanning range of $230 \mathrm{~km}$. Figure 3 reveals that GJ-producing storm A composed of rapidly evolving multi-cell convective elements. These cells reached echo tops of approximately 14 $\mathrm{km}$ (for the limitation of the paper, figures were not shown), while radar echo top with reflectivity of $45 \mathrm{dBZ}$ were estimated to reach $12-14 \mathrm{~km}$. The maximum radar echo top of storm A was about $17 \mathrm{~km}$ at 20:19, a little higher than that of $\mathrm{Su}$ et al. [18], indicating convection in storm A at this time was very strong and in good agreement with previous studies [17,18]. In addition, results from Qingdao radio sounding data (the distance between the storm and Qingdao station was about $100 \mathrm{~km}$, this is the nearest station we could found) show that the CAPE (Convective Available Potential Energy) value was $1294 \mathrm{~J} / \mathrm{kg}$ at 20:00 on $12 \mathrm{Au}-$ gust, and decreased to $363 \mathrm{~J} / \mathrm{kg}$ at 08:00 on 13 August, indicating a lot of energy was consumed and the convection was also strong.

Further analysis shows that GJ occurred in the storm developing stage. In order to clearly show the vertical structure of the GJ-producing storm A, vertical cross section along the GJ direction (line L1, L2 in Figure 3) were made. It can be seen from the figure that convection in storm A was very strong in a time period containing the GJ. Analysis of sprite-producing storm B shows that sprites occurred in the storm mature-to-dissipating stage, consistent with previous study in this region [14]. Detailed comparative analysis between sprite occurring time and the lightning location network shows that two parental CGs for sprites occurred at
19:51:15 and 19:56:18 located in stratiform region with radar reflectivity of about 25-30 dBZ (labeled with black+ in 19:55 in storm B in Figure 3), which is also in agreement with previous study [14]. Similarly, vertical cross section along the parental CG location (line L3, L4 in Figure 3) was made. Compared with GJ-producing storm A, no significant convective activity was found in stratiform region in spriteproducing storm $\mathrm{B}$.

\section{Characteristics of lightning activity in GJ-producing and sprite-producing storms}

The lightning activities are important information during the evolution of the thunderstorm. Characteristics of lightning flashes of the GJ-producing and sprite-producing storms will be analyzed by using data from lightning location network provided by Shandong Meteorological Bureau. Since two different storms produced two different types of TLEs, the lightning activities of storm A and B will be analyzed individually. In order to compare with other results, the same algorithm as other study [19] is used to combine return strokes into a flash, that is, series of strokes occurring within $10 \mathrm{~km}$ and $1 \mathrm{~s}$ from each other were grouped as a flash. Figure 5(a) and (b) shows the evolutions of CG flash rate every five minutes between 19:00 and 21:00 ("local time" in the figure is Beijing time) for storm A and B, respectively. The red line stands for positive CGs and blue line for negative CGs, and the GJ occurrence time (labeled GJ in the figure) and sprite time period (labeled Sprites in the figure) were also shown. Figure 5 indicated that $+\mathrm{CG}$ flash rate increased slightly before the GJ, in agreement with Van der Velde et al. [19]. But the ratio of -CG over $+\mathrm{CG}$ is much higher than that reported by Van der Velde et al. [19]. Meanwhile, Figure 5(a) shows that -CG dominated around the time when GJ occurred, which was different from Van der Velde et al. [19], in which +CG dominated in time window containing GJ. Van der Velde et al. [19] analyzed $+\mathrm{CG}$ with peak current larger than $10 \mathrm{kA}$ and lower than $10 \mathrm{kA}$, respectively, and got almost equal $+\mathrm{CG}$ and $-\mathrm{CG}$ flash rate (as shown in Figure 7 in their paper). Therefore, we could suspect that $+\mathrm{CG}$ flash rate in their study would be much larger than that of -CG if they did not classify + CGs according to the peak current value and all of the +CGs are considered. Therefore, positive CG dominated during the time period centered at GJ in Van der Velde et al. [19], which was different from this study. The above discussion shows that lightning activities of GJ-producing storms have wide diversity.

Figure 6 shows the plots of CGs in 10 min (between 20:11 and 20:21 Beijing time) centered at the GJ event. The results show that only two +CGs occurred in the camera FOV, but 690 -CGs occurred in the same time period. Considering that the combining algorithm (series of strokes occurring within $10 \mathrm{~km}$ and $1 \mathrm{~s}$ from each other were grouped 

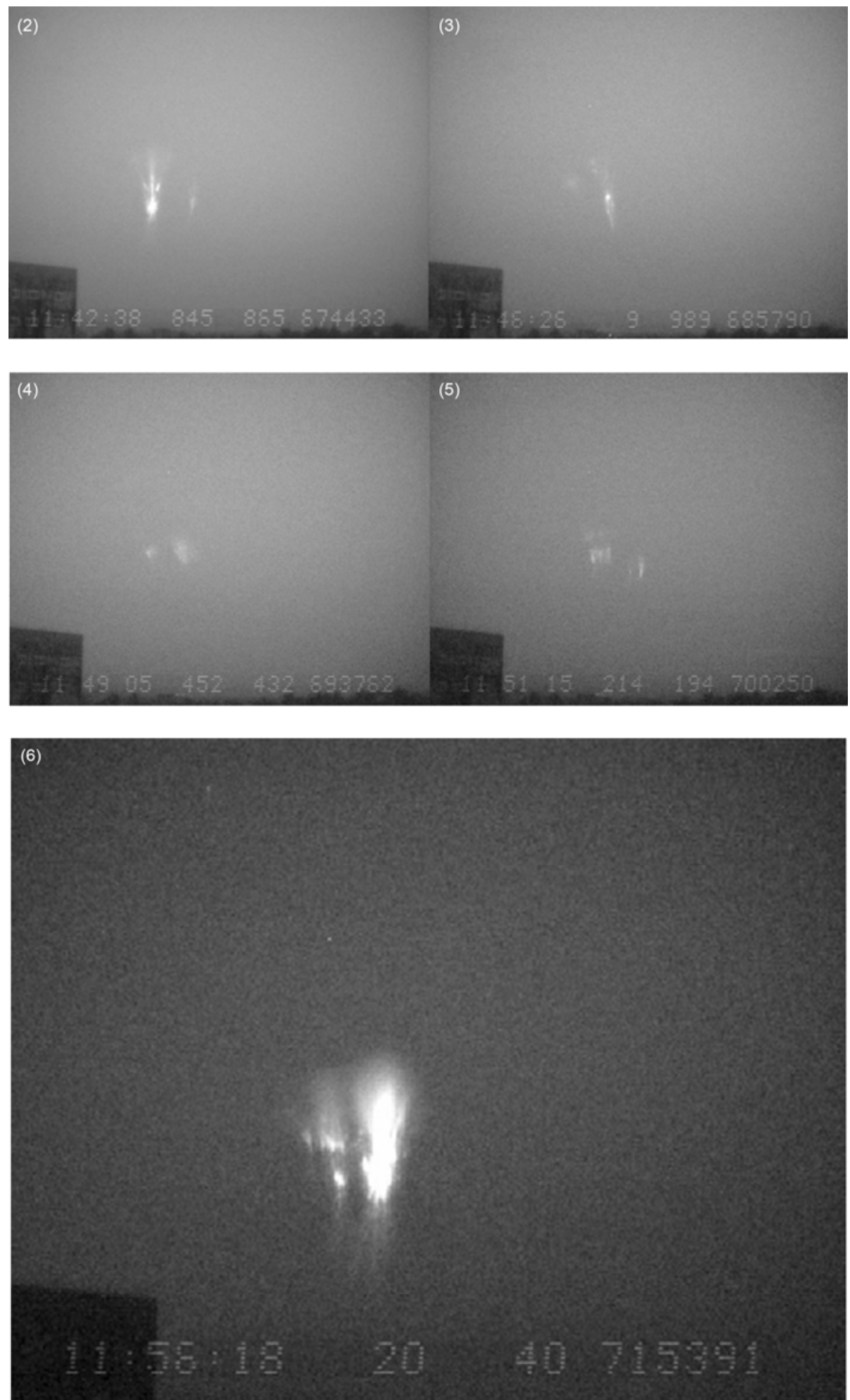

Figure 4 Images of the five sprites, with the sequence as indicated in Table 1.

as a flash) used may be subjective to some extent, the return strokes (not a flash) were directly analyzed (for the limitation of the paper, figures were not shown), but there were still two positive strokes in the camera FOV. Further analysis showed that no +CGs occurred 5 minutes before the GJ, which was also different from results obtained by Van der Velde et al. [19], in which +CGs increased and-CGs ceased 4 minutes before the GJ. Positive CG strokes with peak current less than $10 \mathrm{kA}$ are likely to be intracloud flashes falsely identified by the NLDN (National Lightning Detection 

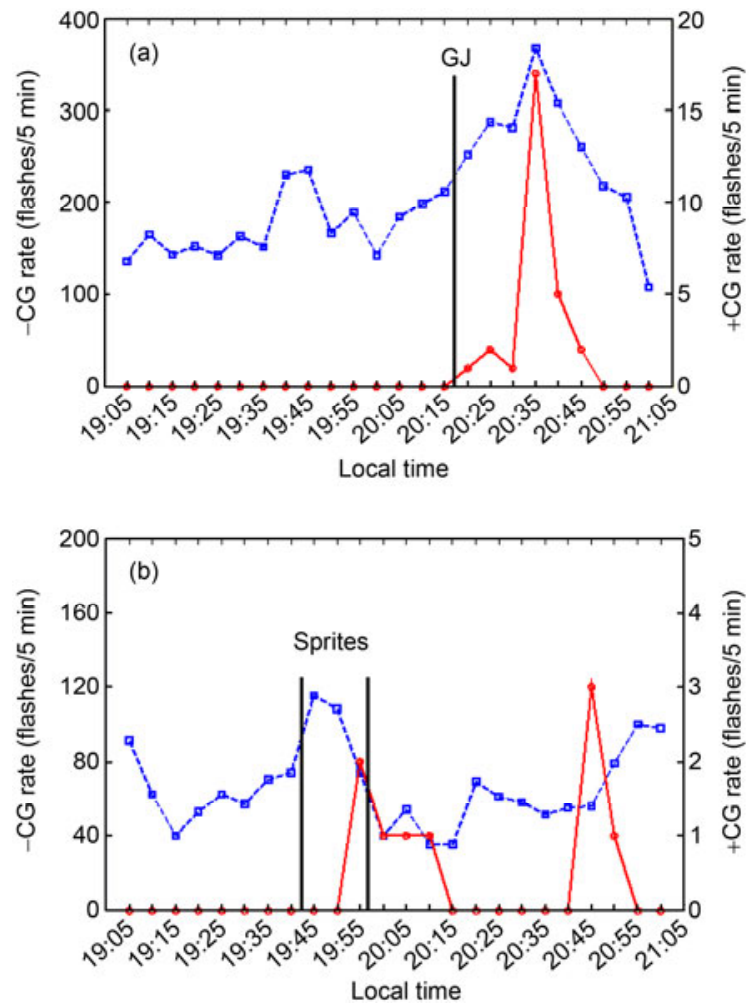

Figure 5 Evolution of CG flash rate every 5 minutes between 19:00 and 21:00 on 12 August, 2010. (a) Lightning flash rate for storm A; (b) lightning flash rate for storm B. The GJ occurrence time (labeled GJ) and sprite time period (labeled Sprites) are shown in the figure. Local time in the figure is Beijing time.

Network) system [27]. Similar problems are expected in lightning data in this paper, that is, some intracloud flashes were considered as positive CGs in this study. Even so, + CG flash rate was still much lower than that of Van der Velde et al. [19]. Results in Soula et al. [22] showed that no CGs occurred in tens of seconds before the GJ, and they suspected that the GJ was caused by intracloud lightning, in agreement with results obtained by Krehbiel et al. [28], which was published in Nature. Further analysis on light- ning location network data shows that 25 negative CGs occurred in 20 seconds before the GJ. The above analysis further confirmed that GJ-producing storms have wide diversity and further studies are needed. Figure 5(a) shows that both of + CGs and -CGs reached a peak at 20:35, which resulted from the storm intensification that could be seen clearly from Doppler radar reflectivity image. The decrease of negative CGs and increase of positive CGs shown in Figure 5(b) during the sprite time period was consistent with previous studies $[14,26]$.

\section{Discussions and conclusions}

One GJ occurred over thunderstorm in mainland China is reported for the first time in this paper. This GJ was also the furthest from the equator documented over summer thunderstorm (storm center located at $35.6^{\circ} \mathrm{N}, 119.8^{\circ} \mathrm{E}$ ) so far. The results showed that the recorded GJ was Type-I and its top altitude was estimated to be about $89 \mathrm{~km}$. The GJ-producing storm was a multi-cell thunderstorm and reflectivity with $45 \mathrm{dBZ}$ was estimated to reach $12-14 \mathrm{~km}$. The maximum radar echo top reached up to $17 \mathrm{~km}$ three minutes after the GJ occurred, indicating that strong convections occurred during the time period containing the GJ.

Different from previous study in which positive CGs dominated during the time period containing GJ, in this paper negative CGs dominated during the whole evolution of the GJ-producing storm, indicating that lightning characteristics of GJ-producing storm have a wide diversity. Also different from previous study in which one storm produced both GJ and sprites, in this study two different storms produced two different types of TLEs, and one storm produced one GJ and the other storm produced five sprites. These results enriched our knowledge of GJ-producing storms. In addition, previous cases of GJ were in tropical, subtropical, or winter regions, however, GJ in this study was in midlatitude region and was outside the effective coverage area $\left(30^{\circ} \mathrm{S}-30^{\circ} \mathrm{N}\right)$ of ISUAL instruments onboard the FORMOSAT
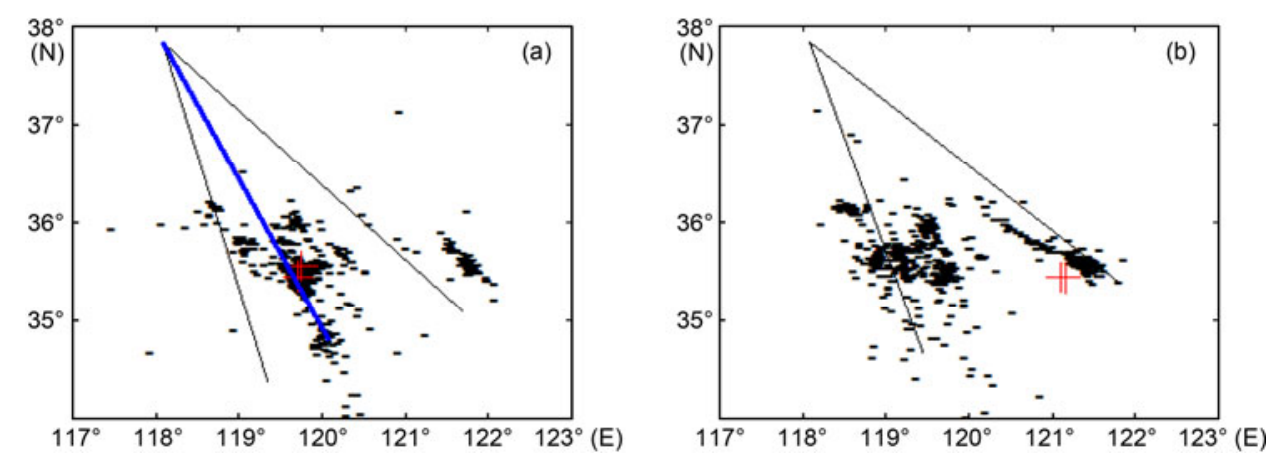

Figure 6 Distribution of CGs in GJ and sprite time period. (a) Plot of +CGs and -CGs between 20:11 and 20:21 Beijing time centered at the GJ; (b) plot of +CGs and -CGs between 19:42 and 19:57 during which 5 sprites occurred. The red + stands for +CG, and black - stands for -CG. The two black lines represent the range of the line-of-sight extending from the observation site, that is, the camera FOV. The blue line is the GJ azimuth in the FOV. 
II satellite. Therefore, results in this study could be considered as a useful additional reference for GJ studies.

GJ establishes direct electrical connection between the thunderstorm and ionosphere, and transfers tens to hundreds of Coulomb from the thundercloud to the ionosphere which is much larger than that in ordinary CGs, leading to a direct effect on the ionosphere. Therefore, study on GJ will provide necessary input parameters for the global electric circuit. In addition, the energy of each GJ released will be on the order of tens of MJ, which will pose a serious threat on the aircraft flying in the near space. Meanwhile, tens of MJ energy will cause violent chemical reaction in the region where GJ occurs, leading to significant changes of the atmospheric physical environment in the same region. As a newly discovered discharge, many scientific questions associated with GJ are not fully understood due to the limited number of cases. For example, what is the ionization level of the atmosphere in GJ region? How high is the electron energy in GJ region? What is the formation condition of the three types of GJs? What causes the three different stages of the GJs? Why GJ has tree-like or grape-like shapes? And what are the causes for different shapes? All these questions are important but unsolved yet. In future, further studies will be made on these discharges above thunderstorms by using data analysis and simulation method.

This work was supported by the Special Fund for Public Welfare Industry (GYHY201006005-07), the National Natural Science Foundation of China (40930949, 41175002) and the National Science and Technology Support Projects (2008BAC36B03). All the authors thank the Kochi University and University of Wyoming for providing satellite and radio sounding data.

1 Dong W S, Zhang Y J, Liu X X. Broadband interferometer observations of a triggered lightning. Chin Sci Bull, 2001, 46: 1561-1565

2 Zhang Y J, Krehbiel P R, Liu X S. Polarity inverted intracloud discharges and the electric charge structure of thunderstorm. Chin Sci Bull, 2002, 47: 1192-1195

3 Zhang Y J, Meng Q, Lü W T, et al. Charge structures and cloud-toground lightning discharges characteristics in two supercell thunderstorms. Chin Sci Bull, 2006, 51: 198-212

4 Zhao Z K, Qie X S, Zhang T L, et al. Electric field soundings and the charge structure within an isolated thunderstorm. Chin Sci Bull, 2010, 55: $872-876$

5 Ma M, Tao S C, Zhu B Y, et al. Response of global lightning activity to air temperature variation. Chin Sci Bull, 2005, 50: 2640-2644

6 Qie X S, Toumi R, Zhou Y J. Characteristics of lightning activity in the central region of Qinghai-Tibet Plateau and its response to the convective available potential energy. Chin Sci Bull, 2003, 48: 87-90

7 Yang J, Qie X S, Zhang G S, et al. Magnetic field measuring system and current retrieval in artificially triggering lightning experiment. Radio Sci, 2008, 43, doi: 10.1029/2007RS003753

8 Qie X S, Jiang R B, Wang C X, et al. Simultaneously measured cur- rent, luminosity, and electric field pulses in a rocket-triggered lightning flash. J Geophys Res, 2011, 116, doi: 10.1029/2010JD015331

9 Kong X Z, Qie X S, Zhao Y. Characteristics of downward leader in a positive cloud-to-ground lightning flash observed by high-speed video camera and electric field changes. Geophys Res Lett, 2008, 35, doi: 10.1029/2007GL032764

10 Yuan T, Qie X. Study on lightning activity and precipitation characteristics before and after the onset of the South China Sea summer monsoon, J Geophys Res, 2008, 113, doi: 10.1029/2007JD009382

11 Qie X S, Zhang T L, Zhang G S, et al. Electrical characteristics of thunderstorms in different plateau regions of China. Atmos Res, 2009, 91: 244-249

12 Franz R C, Nemzek R J, Winckler J R. Television image of a large upward electrical discharge above a thunderstorm system. Science, 1990, 249: 48-51

13 Wu M L, Xu J Y. A time-dependent quasi-three-dimensional QEF model of red sprites (in Chinese). Chin J Geophys, 2005, 48: 480486

14 Yang J, Qie X S, Zhang G S, et al. Red sprites over thunderstorms in the coast of Shandong Province. Chin Sci Bull, 2008, 53: 1079-1086

15 Boeck W L, Vaughan O H Jr, Blakeslee R, et al. Lightning induced brightening in the airglow layer. Geophys Res Lett, 1992, 19: 99-102

16 Wescott E M, Sentman D D, Osborne D L, et al. Preliminary results from the Sprites94 aircraft campaign: 2. Blue jets. Geophys Res Lett, 1995, 22: 1209-1212

17 Pasko V P, Stanley M A, Mathews J D, et al. Electrical discharge from a thunderstorm top to the lower ionosphere. Nature, 2002, 416: 152-154

18 Su H T, Hsu R R, Chen A B, et al. Gigantic jets between a thundercloud and the ionosphere. Nature, 2003, 423: 974-976

19 Van der Velde O A, Lyons W A, Nelson T E, et al. Analysis of the first gigantic jet recorded over continental North America. J Geophys Res, 2007, 112, doi: 10.1029/2007JD008575

20 Cummer S A, Li J, Han F, et al. Quantification of the troposphere-toionosphere charge transfer in a gigantic jet. Nat Geosci, 2009, 2: $617-620$

21 Chou J K, Tsai L Y, Kuo C L, et al. Optical emissions and behaviors of the blue starters, blue jets, and gigantic jets observed in the Taiwan transient luminous event ground campaign. J Geophys Res, 2011, 116, doi: 10.1029/2010JA016162

22 Soula S, Van der Velde O A, Montanya J, et al. Gigantic jets produced by an isolated tropical thunderstorm near Réunion Island. $\mathrm{J}$ Geophys Res, 2011, 116, doi: 10.1029/2010JD015581

23 Van der Velde O A, József Bór, Li J B, et al. Multi-instrumental observations of a positive gigantic jet produced by a winter thunderstorm in Europe. J Geophys Res, 2010, 115, doi: 10.1029/2010JD014442

24 Chen A B, Kuo C L, Lee Y J, et al. Global distributions and occurrence rates of transient luminous events. J Geophys Res, 2008, 113, doi:10.1029/2008JA013101

25 Chou J K, Kuo C L, Tsai L Y, et al. Gigantic jets with negative and positive polarity streamers. J Geophys Res, 2010, 115, doi: 10.1029/ 2009JA014831

26 Soula S, Van der Velde O A, Montanya J, et al. Analysis of thunderstorm and lightning activity associated with sprites observed during the EuroSprite campaigns: Two case studies. Atmos Res, 2009, 91: 514-528

27 Cummins K L, Murphy M J, Bardo E A, et al. A combined TOA/ MDF technology upgrade of the U.S. National Lightning Detection Network. J Geophys Res, 1998, 103: 9035-9044

28 Krehbiel P R, Riousset J A, Pasko V P, et al. Upward electrical discharges from thunderstorms. Nat Geosci, 2008, 1: 233-237

Open Access This article is distributed under the terms of the Creative Commons Attribution License which permits any use, distribution, and reproduction in any medium, provided the original author(s) and source are credited. 